\title{
Surgical Management of aseptic Femoral Shaft Non-union after Intramedullary Fixation
}

\author{
Eissa Ragheb Refaie ${ }^{1}$, Ahmed Abd El hamidShamma, Abdullah Abu Senna ${ }^{1}$, Mohamed Negm ${ }^{1}$, Ahmed \\ Abd El sattar Eltarabany ${ }^{2}$ \\ ${ }^{1}$ Department of orthopedic, Faculty of Medicine, Al-Azhar University, Cairo,Egypt \\ ${ }^{5}$ Department of orthopedic, Mashtoul-Elsouk general hospital Ministry of Health, Sharkia, Egypt \\ Corresponding author: Ahmed Abd El sattar, Tel: +01000955389, Email: ahmedeltarabany@ gmail.com
}

\begin{abstract}
Background: Several treatment modalities are available for handling of femoral nonunion after intramedullary nailing. These alternatives include nail dynamisation, external fixation, exchange nailing and Plate osteosynthesis. This treatment can be used as augmentation technique over a previous used intramedullary nail, with or without bone grafting. Objective: To evaluate the outcome of femoral nonunion after intramedullary fixation by locked nail and management of 30 cases of aseptic femoral nonunion with nail exchange or augmentation with plate. Patients and Methods: We reviewed 30 patients with femoral fracture nonunion after interlocking intramedullary nailing treated either with exchange nailing with or without bone graft or plate augmentation and bone grafting with the nail in situ. The mean time from primary nailing to exchange nailing or plate augmentation and bone grafting was $9.80 \pm 5.45$ months for achieving stability of the fracture. We did exchange nailing with larger diameter nail or applying DCP plate on the lateral aspect of the femur. Results: 27 patients achieved solid union in time ranged from 6-12 months with mean of 7.54 \pm 2.18 . Conclusion: Exchange reamed intramedullary nailing has low morbidity, may obviate the need for additional bone grafting, and allows full weight-bearing and active rehabilitation provides extremely rigid fixation, and provides reason to allow patients to bear weight early in the postoperative period. Bone graft could be precisely placed in the fracture site if necessary.
\end{abstract}

\section{INTRODUCTION}

Despite the advances in trauma care, improved surgical techniques, newer implants and the evolution of new adjuvant to healing, biologic agents, nonunion still occur and are often a result of a high energy initial trauma. Femoral nonunion represents a serious socioeconomic problem for the patient, associated with prolonged patient morbidity, gait abnormality, inability to return to work, re-operations and psycho-emotional impairment. It moreover stands for a treatment challenge for the orthopedic surgeon.

Union is considered delayed when healing has not advanced at the average rate for the location and type of fracture (usually 3-6 months). Classification of nonunion is based on radiographic and scintigraphic appearance of the fracture site ${ }^{(2)}$. It is divided into, hypertrophic or viable and, atrophic or non-viable sub-types ${ }^{(3)}$.

The diagnostic modalities are: patient history, including the date of injury, details of the initial and subsequent treatment, patient's nutritional status and associated medical problems is essential before beginning the diagnostic workup. The patient's description of a painful and mobile fracture site may be the first sign in the detection of the nonunion. Potential risk factors such as smoking, use of nonsteroidal antiinflammatory drugs and the physical examination must assess the presence of pain and/or motion in the area of the nonunion or pain in the adjacent joints. The patient should also be examined in the weight bearing position. Antalgic gait and/or the presence of ambulatory assistive equipment may be present. Static and dynamic functional alignment in the frontal, horizontal and sagittal planes must carefully be assessed, as well as range of motion of the adjacent joints. Neurovascular evaluation of the lower extremity is essential. The evaluation should include peripheral pulses and skin temperature ${ }^{(5)}$.

The radiographic evaluation must include anteroposterior and lateral views and with the beam centered on the deformity. The diagnosis of a nonunion is based on the absence of bridging bone at the fracture site and persistence of the fracture line. Computerized tomography (CT) has replaced plain tomography, and may be helpful in the exact measurement of the anatomic and mechanical axis of the limb ${ }^{(5)}$.

Infection should always be investigated in the presence of femoral nonunion. Laboratory tests include a complete blood test, erythrocyte sedimentation rate and C-reactive protein levels. Inappropriate mechanical environment of the fracture (inadequate fracture stability), insufficient blood supply (avascularity), bone loss are the main reasons for the development of a nonunion. In some cases, despite the appropriate treatment, there is no evident reason ${ }^{(6)}$. 


\section{PATIENTS AND METHODS}

This study was carried out on 30 patients with ununited fracture femur after interlocking femoral nail, operated upon either by exchange nailing or augmentation plate over the nail in the period between July 2012 and July 2018. The study was approved by the Ethics Board of AlAzhar University.

The cases were 25 males and 5 females, and their ages ranged from19-51 years with a mean age of 34 years. In exchange nailing group,

15 patients had been operated upon by exchange nailing Closed reamed intramedullary nailing as (figure 1) combined with or without open bone grafting. The closed technique consisted of replacement of a larger size reamed nail (in 13 cases). The open method consisted of local debridement, maintaining local stability by larger size reamed nail, and bone grafting (in 2cases) and in augmentation plate group15 patients had been operated upon by augmentation plating over the preexisting nail with bone graft (14 cases)(figure 2) or without bone grafting (1 case).
All the patients were complaining of a painful fracture with 16 right sided fracture and 14 left sided fracture, The duration of nonunion range between6-36 months, 23 patients were smokers, 1 patient was diabetic, and 4 patients were hypertensive and 19 patients were on NSAIDs intake, 7 patients presented with subtrochanteric fracture, 5 patients with fracture junction middle distal third, 15 patients with midshaft fracture and 3 patients with distal third fracture and 3 patients had complex fracture,20 patients had simple fracture and 7 patients with wedge fracture, 6 patients had preoperative limb length inequality less than $2 \mathrm{~cm}, 14$ patients can bear and 16 patients cannot and 4patients had history of previous open fracture and 5 patients had a history of previous open reduction. 16patients had hypertrophic nonunion and 14 patients had atrophic nonunion and14 patients had implant failure in the form of broken locked screws. 4 patients had associated injuries.

Table (1): Clinical detail of the patients with femur nonunion in exchange nailing group.

\begin{tabular}{|c|c|c|c|c|c|c|c|c|c|c|c|c|c|c|c|}
\hline No. & Age(years) & sex & side & $\begin{array}{c}\begin{array}{c}\text { Duration } \\
\text { of } \\
\text { nonunion }\end{array} \\
\end{array}$ & Level of fracture & $\begin{array}{c}\text { Pattern } \\
\text { of } \\
\text { fracture }\end{array}$ & $\begin{array}{c}\text { Weight } \\
\text { bearing }\end{array}$ & \begin{tabular}{|c|} 
Limb \\
length \\
inequality \\
\end{tabular} & $\begin{array}{l}\text { Initial } \\
\text { injury }\end{array}$ & $\begin{array}{c}\text { Initial } \\
\text { reduction }\end{array}$ & $\begin{array}{c}\text { Type of } \\
\text { nonunion }\end{array}$ & $\begin{array}{c}\text { Implant } \\
\text { failure }\end{array}$ & $\begin{array}{c}\text { Associated } \\
\text { injuries }\end{array}$ & $\begin{array}{c}\text { Associated } \\
\text { medical } \\
\text { comorbidities }\end{array}$ & smoking \\
\hline 1 & 30 & $\mathrm{M}$ & $\mathrm{L}$ & 20 & Subtrochanteric & simple & bear & $-\mathrm{ve}$ & Closed & closed & Atrophic & $-\mathrm{ve}$ & $+\mathrm{ve}$ & $+\mathrm{ve}$ & $+\mathrm{ve}$ \\
\hline 2 & 30 & $\mathrm{M}$ & $\mathrm{L}$ & 24 & Middle distal & complex & cannot & $-\mathrm{ve}$ & Closed & Open & atrophic & $+\mathrm{ve}$ & $+\mathrm{ve}$ & $+\mathrm{ve}$ & $+\mathrm{ve}$ \\
\hline 3 & 27 & $\mathrm{M}$ & $\mathrm{R}$ & 8 & Sub trochanteric & simple & bear & $-\mathrm{ve}$ & Closed & open & \begin{tabular}{|l|} 
hypertrophic \\
\end{tabular} & $+\mathrm{ve}$ & $-\mathrm{ve}$ & $+\mathrm{ve}$ & $+\mathrm{ve}$ \\
\hline 4 & 55 & $\mathrm{~F}$ & $\mathrm{R}$ & 6 & sub trochanteric & simple & With aid & $+\mathrm{ve}$ & Closed & closed & Atrophic & $+\mathrm{ve}$ & $-\mathrm{ve}$ & $+\mathrm{ve}$ & $-\mathrm{ve}$ \\
\hline 5 & 40 & $\mathrm{M}$ & $\mathrm{L}$ & 6 & sub trochanteric & simple & With aid & $-\mathrm{ve}$ & Closed & closed & hypertrophic & $+\mathrm{ve}$ & $-\mathrm{ve}$ & $+\mathrm{ve}$ & $+\mathrm{ve}$ \\
\hline 6 & 28 & $\mathrm{M}$ & $\mathrm{R}$ & 7 & Mid shaft & simple & bear & $-\mathrm{ve}$ & closed & closed & hypertrophic & $-\mathrm{ve}$ & $-\mathrm{ve}$ & $-\mathrm{ve}$ & $+\mathrm{ve}$ \\
\hline 7 & 46 & $\mathrm{~F}$ & $\mathrm{~L}$ & 8 & Mid shaft & wedge & $\begin{array}{l}\text { With aid } \\
\end{array}$ & $-\mathrm{ve}$ & closed & closed & Atrophic & $-\mathrm{ve}$ & $-\mathrm{ve}$ & $+\mathrm{ve}$ & $-\mathrm{ve}$ \\
\hline 8 & 27 & $\mathrm{M}$ & $\mathrm{L}$ & 6 & midshaft & wedge & $\begin{array}{l}\text { With aid } \\
\end{array}$ & $-\mathrm{ve}$ & open & open & Atrophic & $+\mathrm{ve}$ & $-\mathrm{ve}$ & $-\mathrm{ve}$ & $+\mathrm{ve}$ \\
\hline 9 & 30 & $\mathrm{M}$ & $\mathrm{L}$ & 6 & midshaft & simple & bear & $-\mathrm{ve}$ & closed & closed & Atrophic & $-\mathrm{ve}$ & $-\mathrm{ve}$ & $-\mathrm{ve}$ & $+\mathrm{ve}$ \\
\hline 10 & 38 & $\mathrm{M}$ & $\mathrm{L}$ & 6 & midshaft & simple & With aid & $-\mathrm{ve}$ & closed & closed & hypertrophic & $-\mathrm{ve}$ & $-\mathrm{ve}$ & $+\mathrm{ve}$ & $+\mathrm{ve}$ \\
\hline 11 & 45 & $\mathrm{~F}$ & $\mathrm{~L}$ & 10 & midshaft & simple & bear & $-\mathrm{ve}$ & \begin{tabular}{|l|} 
closed \\
\end{tabular} & closed & hypertrophic & $-\mathrm{ve}$ & $-\mathrm{ve}$ & $+\mathrm{ve}$ & $-\mathrm{ve}$ \\
\hline 12 & 22 & $\mathrm{M}$ & $\mathrm{L}$ & 6 & subtrochanteric & simple & bear & $-\mathrm{ve}$ & \begin{tabular}{|l|} 
closed \\
\end{tabular} & closed & hypertrophic & $-\mathrm{ve}$ & $-\mathrm{ve}$ & $-\mathrm{ve}$ & $+\mathrm{ve}$ \\
\hline 13 & 21 & $\mathrm{M}$ & $\mathrm{R}$ & 12 & midshaft & simple & With aid & $-\mathrm{ve}$ & closed & closed & Atrophic & $+\mathrm{ve}$ & $-\mathrm{ve}$ & $-\mathrm{ve}$ & $-\mathrm{ve}$ \\
\hline 14 & 22 & $\mathrm{M}$ & $\mathrm{R}$ & 12 & midshaft & simple & With aid & $-\mathrm{ve}$ & open & open & \begin{tabular}{|l} 
hypertrophic \\
\end{tabular} & $-\mathrm{ve}$ & $-\mathrm{ve}$ & $+\mathrm{ve}$ & $+\mathrm{ve}$ \\
\hline 15 & 28 & $\mathrm{M}$ & $\mathrm{R}$ & 10 & distal & simple & bear & $-\mathrm{ve}$ & $-\mathrm{ve}$ & closed & \begin{tabular}{|l|} 
hypertrophic \\
\end{tabular} & $-\mathrm{ve}$ & $+\mathrm{ve}$ & $+\mathrm{ve}$ & $+\mathrm{ve}$ \\
\hline
\end{tabular}

$\mathrm{M}=$ Male. $\mathrm{F}=$ Female. $\mathrm{R}=$ Right. $\mathrm{L}=$ left No. =number $-\mathrm{ve}=$ Negative and +ve= Positive

Table (2): Clinical details of the patients with femur nonunion in augmentation plate group.

\begin{tabular}{|c|c|c|c|c|c|c|c|c|c|c|c|c|c|c|c|c|}
\hline No. & Age & sex & side & $\begin{array}{c}\text { Duration of } \\
\text { nonunion }\end{array}$ & Level of fracture & $\begin{array}{c}\text { Pattern of } \\
\text { fracture }\end{array}$ & $\begin{array}{l}\text { Weight } \\
\text { bearing }\end{array}$ & $\begin{array}{c}\text { Limb } \\
\text { length } \\
\text { inequality }\end{array}$ & $\begin{array}{l}\text { Initial } \\
\text { injury }\end{array}$ & $\begin{array}{c}\text { Initial } \\
\text { reduction }\end{array}$ & $\begin{array}{c}\text { Type of } \\
\text { nonunion }\end{array}$ & $\begin{array}{l}\text { Implant } \\
\text { failure }\end{array}$ & $\begin{array}{c}\text { Associated } \\
\text { injuries }\end{array}$ & $\begin{array}{c}\text { Associate } \\
\text { medical } \\
\text { comorbidities }\end{array}$ & smoking & \\
\hline 1 & 25 & $\mathrm{M}$ & $\bar{R}$ & 6 & distal & simple & bear & $-\mathrm{Ve}$ & Closed & open & hypertrophic & $-\mathrm{Ve}$ & $-\mathrm{ve}$ & $+\mathrm{Ve}$ & $+\mathrm{Ve}$ & \\
\hline 2 & 27 & $\mathrm{M}$ & $\mathrm{R}$ & 6 & midshaft & complex & cannot & $+\mathrm{Ve}$ & Open & closed & atrophic & $+\mathrm{Ve}$ & $+\mathrm{ve}$ & $+\mathrm{Ve}$ & $+\mathrm{Ve}$ & \\
\hline 4 & 35 & $\mathrm{M}$ & $\mathrm{L}$ & 12 & midshaft & simple & bear & $-\mathrm{Ve}$ & closed & closed & hypertrophic & $+\mathrm{Ve}$ & $-\mathrm{ve}$ & $+\mathrm{Ve}$ & $+\mathrm{Ve}$ & \\
\hline 5 & 19 & $\mathrm{M}$ & $\mathrm{R}$ & 6 & subtrochanteric & Simple & Bear with aid & $-\mathrm{Ve}$ & closed & closed & hypertrophic & $+\mathrm{Ve}$ & $-\mathrm{ev}$ & $-\mathrm{Ve}$ & $+\mathrm{Ve}$ & \\
\hline 6 & 28 & $\mathrm{M}$ & $\mathrm{R}$ & 12 & Midshaft & Simple & bear & $-\mathrm{Ve}$ & closed & closed & hypertrophic & $-\mathrm{Ve}$ & $-\mathrm{ve}$ & $+\mathrm{Ve}$ & $+\mathrm{Ve}$ & \\
\hline 7 & 43 & $\mathrm{M}$ & $\mathrm{R}$ & 36 & Middle,distal third & Simple & cannot & $+\mathrm{Ve}$ & closed & closed & hypertrophic & $+\mathrm{Ve}$ & $-\mathrm{ve}$ & $-\mathrm{Ve}$ & $+\mathrm{Ve}$ & \\
\hline 8 & 34 & $\mathrm{M}$ & $\mathrm{L}$ & 6 & \begin{tabular}{|l|} 
Middle,distal third \\
\end{tabular} & Simple & bear & $-\mathrm{Ve}$ & closed & closed & hypertrophic & $+\mathrm{Ve}$ & $-\mathrm{ve}$ & $+\mathrm{Ve}$ & $+\mathrm{Ve}$ & \\
\hline 9 & 40 & $\mathrm{M}$ & $\mathrm{L}$ & 7 & subtrochanteric & wedge & cannot & $+\mathrm{Ve}$ & closed & closed & atrophic & $+\mathrm{Ve}$ & $-\mathrm{ve}$ & $+\mathrm{Ve}$ & $+\mathrm{Ve}$ & \\
\hline 10 & 42 & $\mathrm{~F}$ & $\mathrm{R}$ & 7 & midshaft & wedge & Bear with aid & $-\mathrm{Ve}$ & open & closed & Atrophic & $+\mathrm{Ve}$ & 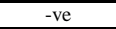 & $+\mathrm{Ve}$ & $-\mathrm{Ve}$ & \\
\hline 11 & 44 & $\mathrm{M}$ & $\mathrm{L}$ & 6 & Middle,distal third & wedge & bear & $-\mathrm{Ve}$ & closed & closed & atrophic & $-\mathrm{Ve}$ & -ve & $+\mathrm{Ve}$ & $+\mathrm{Ve}$ & \\
\hline 12 & 33 & $\mathrm{M}$ & $\mathrm{R}$ & 6 & distal & simple & Bear with aid & $-\mathrm{Ve}$ & closed & closed & hypertrophic & $-\mathrm{Ve}$ & -ve & $-\mathrm{Ve}$ & $+\mathrm{Ve}$ & \\
\hline 13 & 28 & $\mathrm{M}$ & $\mathrm{R}$ & 6 & midshaft & simple & bear & $-\mathrm{Ve}$ & closed & closed & atrophic & $-\mathrm{Ve}$ & $-\mathrm{ve}$ & $+\mathrm{Ve}$ & $+\mathrm{Ve}$ & \\
\hline 14 & 23 & $\mathrm{M}$ & $\mathrm{R}$ & 7 & Middle distal & wedge & bear & $-\mathrm{Ve}$ & closed & closed & atrophic & $-\mathrm{Ve}$ & $-\mathrm{ve}$ & $-\mathrm{Ve}$ & $+\mathrm{Ve}$ & \\
\hline 15 & 51 & $\mathrm{~F}$ & $\mathrm{R}$ & 8 & midshaft & complex & Bear with aid & $+\mathrm{Ve}$ & closed & closed & hypertrophic & $+\mathrm{Ve}$ & $-\mathrm{ve}$ & $-\mathrm{Ve}$ & $-\mathrm{Ve}$ & \\
\hline
\end{tabular}




\section{RESULTS}

The patients started to weight bear after surgery by mean of 6-10 weeks, 1 patient had superficial infection treated with intravenous antibiotics. There was no implant failure postoperatively and the range of motion was equal to that before operation in 11 patients and increased in 19 patients and the time of union ranged from 6-12 months. The follow up period ranged from 5-10 months, with 27 patients had complete union and 3 cases had nonunion.

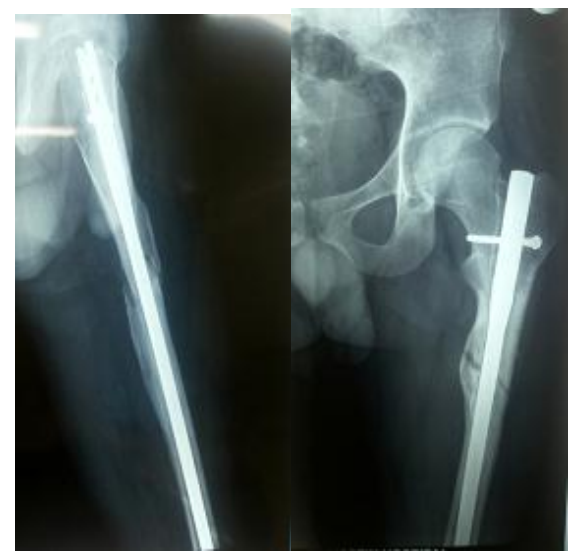

Fig. (1): Showing femur nonunion after intramedullary nailing.

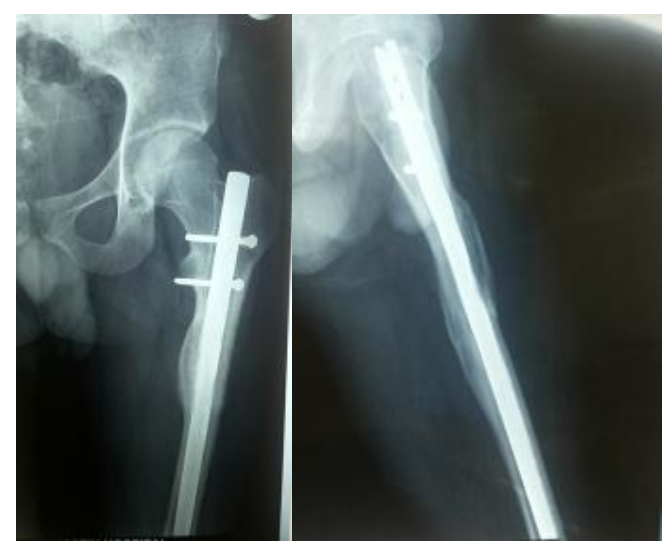

Fig. (2): Showing complete union after closed exchange nailing.

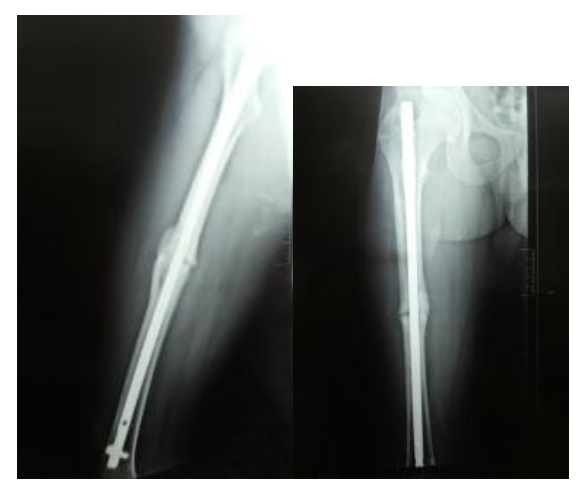

Fig. (3): Showing femur nonunion after intramedullary nailing.

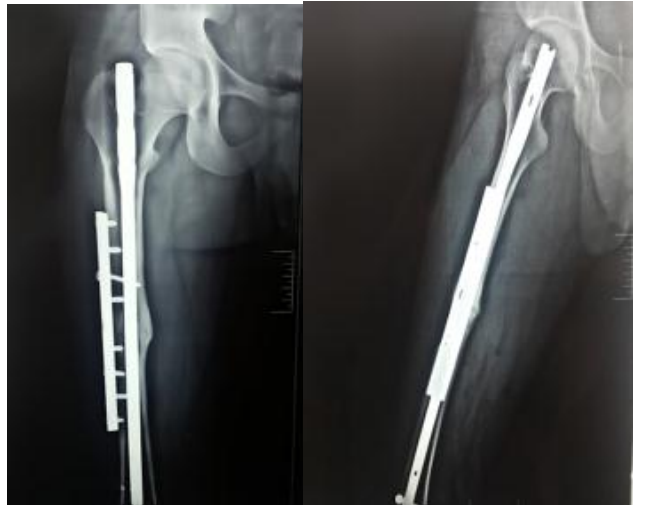

Fig. (4): Showing complete union after augmentation by plate and bone graft.

\section{DISCUSSION}

Femoral nonunions are reported to occur in up to $10 \%$ of femur fractures. Factors responsible for non-union include the severity of trauma, degree of comminution and technical problems in primary intramedullary nailing and associated medical problems.

Fracture is considered ununited after six months of primary nailing. The therapeutic concepts comprise improvement of impaired biology and enhancement of stability at the nonunion site This includes augmentation of local biology and vascularity, correction of axis deviation, rigid internal fixation with compression of the nonunion, which all optimize the conditions for bone healing.

Exchange nailing for the treatment of an ununited femoral fracture included removal of the current intramedullary nail, reaming of the medullary canal, and placement of an intramedullary nail that was larger in diameter than the removed nail. The principal indication for exchange nailing was a nonunion in a long bone of the lower extremity following prior intramedullary nailing. Exchange nailing had been shown to be successful for the treatment of both atrophic and hypertrophic nonunion.

Exchange nailing of an atrophic nonunion may stimulate a healing response and augment mechanical stability. Exchange nailing of a hypertrophic nonunion augments mechanical stability, which is the main requirement to achieve osseous healing. In the decision whether to perform exchange nailing include osseous contact, deformity, infection, and the anatomic site. 
Exchange nailing was the most successful in the treatment of nonunions following closed or open fractures without substantial bone loss. While comminution of the original fracture was not an absolute contraindication to exchange nailing, comminution may decrease the rate of osseous union and increase the time to osseous union.

Key steps for successful healing included closed nonunion treatment correction of axis deviation, limited reaming and biological augmentation by internal reaming graft, and increased rotational and axial stability by insertion of an increased nail diameter and by dynamic compression of the nonunion site. The concept of reamed exchange nailing and closed nonunion therapy resulted in reasonable bone healing of aseptic femoral shaft nonunion and is considered the standard procedure of choice for this nonunion entity.

Exchange reamed intramedullary nailing had low morbidity, may obviate the need for additional bone grafting, and allowed full weight bearing and active rehabilitation.

In this series14 patients achieve union and one patient from 15 patient treated with exchange nailing don't achieve union this female patient 55 year old presented with fracture proximal femur 6 months ago. She is diabetic hypertensive and had history of NSAIDs intake. There is atrophic nonunion and this patient don't achieve union because of osteoporosis, diabetes mellitus

Wu and Chen ${ }^{(7)}$ compared the results of 16 patients treated by closed intramedullary nailing technique and 19 patients by an open technique. The closed technique consisted of replacement of a larger size reamed nail. The open method consisted of local debridement, maintaining local stability, and cancellous bone grafting. Union occurred in $100 \%$ of the patients, as the union period for the closed technique was significantly shorter than with the open technique. Oh et $\boldsymbol{a l} .^{(8)}$ treated fifteen femoral nonunion with dynamically locked reamed nailing with no open bone grafting for a defects less than $50 \%$ of the diameter and immediate weight bearing achieving solid union in $93 \%$ of the cases.

Swanson et al. ${ }^{(9)}$ evaluated the radiographic and clinical outcomes of a systematic approach to exchange nailing for the treatment of aseptic femoral nonunion previously treated with an intramedullary nail. Fifty aseptic femoral nonunion in 49 patients who presented with an intramedullary nail in situ an average of 25 months after the initial fracture nailing were evaluated. Systematic approach includes inserting an exchange nail at least $2 \mathrm{~mm}$ larger in diameter than the in situ nail, using a different manufacturer's nail, static interlocking, correction of any metabolic and endocrine abnormalities, and secondary nail dynamisation in cases showing slow progression toward healing. All 50 femoral nonunion $(100 \%)$ healed after this systematic approach to exchange nailing. The average time to achieve union was 7 months (range, 3-26 months).

Another choice is augmentation of the nail by plate with the nail left in situ to maintain the alignment of the fracture, which could help to maintain stability as a loading-sharing device. Thus, it provides extremely rigid fixation, and provides reason to allow patients to bear weight early in the postoperative period. Bone graft could be precisely placed in the fracture site if necessary. Therefore, this method offers extremely rigid fixation, early mechanical force, and autograft implantation, which promotes bone healing and increases union rate.

The decision for plating with the nail in situ was based on the technical accuracy of the primary nailing. When the nail working length and diameter was adequate and proximal and distal locking screws were Present, then plating was performed with the nail in situ after removal of the locking screws. The DCP plate achieved compression at the fracture site which facilitated union and early weight bearing.

In this series two patients from fifteen patients with femoral nonunion after interlocking nailing undergone augmentation plate with the nail in situ don't achieve union and thirteen patients achieve complete union. Some improvement in the range of motion of the knee occur in all patients but not complete range of motion. Improvement in pain sensation and gait in all patients with complete union.

The first patient that had nonunion is male patient 27 year old, heavy smoker, with history of NSAIDs intake and history of open fracture femur with ipsilateral fracture neck femur 6 months ago treated by interlocking nail and cannulated screws for fracture neck femur. On radiological examination: atrophic nonunion of the diaphyseal fracture and kinked screw in the neck. We do augmentation plate over the nail with realignment of the facture with iliac crest autograft. After follow up 6 months the patient doesn't achieve 
union with probable cause wide area of comminution of the fracture. The graft is not enough for this wide area. Some comminuted parts not fixed by the screws. The plate is not long enough to fulfill sound fixation.

The 2nd patient that had nonunion is male patient 43 year old with history of hypertension, NSAIDs intake, not smoker and history of fracture upper middle third femur 10 months ago with atrophic nonunion treated by plate augmentation and iliac crest autograft. After follow up 6 months the patient doesn't achieve union with probable causes: A big butterfly segment not fixed by the screws of the plate because the femur in this part is narrow and the screw cannot attain the other cortex. While Choi and Kim ${ }^{(\mathbf{1 0})}$ reviewed 15 patients with femoral nonunion after interlocking intramedullary nailing treated with plate augmentation and bone grafting with the nail in situ. The mean time from primary nailing to plate augmentation and bone grafting was 10 months. Applying an AO plate on the Lateral aspect of the femur. The retained nail maintained alignment of the fracture, and plating did not require an extensive surgical approach. In all patients, there was visible motion at the fracture site; however, the motion disappeared after plate augmentation. All patients' achieved radiological solid union at an average of 7.2 months ${ }^{(10)}$.

There are other methods for treatment of nonunion after intramedullary nailing. Percutaneous bone marrow injection provided an alternative to open bone grafting, having least complications, especially for early intervention in the fracturehealing process ${ }^{(11)}$.

The use of bone marrow to accelerate fracture healing is one of the applications of the stem cell technology. It represents a promising method of application of tissue engineering in the orthopedic field, which avoids many of the complications of the traditional bone grafting method commonly used so far.

Dual onlay bone grafts are useful when treating difficult and unusual nonunions or for the bridging of massive defects. Dual grafts provide stability because they grip the small fragment like forceps ${ }^{(11)}$.

\section{CONCLUSION}

In this series, there is no significant difference between groups according to outcome but augmentation plating with autogenous bone grafting might be a better option than exchange nailing for nonisthmal femoral nonunion

\section{REFERENCES}

1. Ioannis D, Angelos $\mathrm{N}$, Christina $\mathrm{M}$ et al. (2011): Diagnostic and treatment modalities in nonunions of the femoral shaft. JINJ., 43(7): 980-988.

2. Lynch JR, Taitsman LA, Barei DP et al. (2008): Femoral nonunion: risk factors and treatment options. J Am Acad Orthop Surg., 16(2):88-97.

3. Lai D, Chen CM, Chiu FY et al. (2007): Reconstruction of juxta-articular huge defects of distal femur with vascularized fibular bone graft and Ilizarov's distraction osteogenesis. J Trauma, 62(1):166-73.

4. Graves ML, Ryan JE, Mast JW (2005): Supracondylar femur nonunion associated with previous vascular repair: importance of vascular exam in preoperative planning of nonunion repair. J Orthop Trauma, 19(8):574-7.

5. Bhattacharyya T, Bouchard KA, Phadke A et al. (2006): The accuracy of computed tomography for the diagnosis of tibial nonunion. J Bone Joint Surg Am., 88(4):692-7.

6. Alt V, Meyer C, Litzlbauer HD et al. (2007): Treatment of a double nonunion of the femur by rhBMP-2. J Orthop Trauma, 21(10):734-7.

7. Wu CC and Chen WJ (2003): Tibial lengthening: technique for speedy lengthening by external fixation and secondary internal fixation. J Trauma, 54(6):1159-65.

8. Oh JK, Bae JH, Oh CW et al. (2008): Treatment of femoral and tibial diaphyseal nonunions using reamed intramedullary nailing without bone graft. Injury, 39(8):952-959.

9. Swanson EA, Garrard EC, Bernstein DT et al. (2015): Results of a systematic approach to exchange nailing for the treatment of aseptic femoral nonunions. J Orthop Trauma, 29(1):21-7

10. Choi YS and Kim KS (2005): Plate augmentation leaving the nail in situ and bone grafting for non-union of femoral shaft fractures. Int Orthop., 29(5):287-90.

11. Hung NN (2012): Basic Knowledge of Bone Grafting, Bone Grafting, Dr Alessandro Zorzi (Ed), cdn. intechopen. com/.../InTech-Basic_knowledge_ of bone_grafting. pdf.\%20Accessed 